\title{
Chrysanthine theoretical thought and notation system The relation between Orality and Textuality
}

\author{
NIKOS ANDRIKOS ${ }^{\star}$ \\ ^Department of Music Studies, University of Ioannina, Greece. - nikoandr@uoi.gr.
}

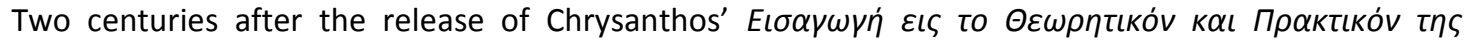

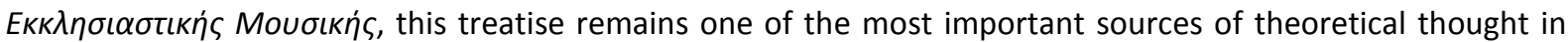
the field of Greek Orthodox Ecclesiastical Music. Moreover, it is widely known that the theoretical essays of Chrysanthos played a catalytic role regarding the structure of the modal system of Octaechia, the formulation of the new Parasemantiki notation, as well as contemporary performance practices. Indeed, Chrysanthos' contribution to the reformation of the notation system as well as the way he attributed the theoretical content of Ecclesiastical Music, influenced the entire theoretical thought that was produced, at least until the last decades of the $19^{\text {th }}$ century ${ }^{1}$. Therefore, despite individual disagreements that were expressed within the psaltic milieu of the $19^{\text {th }}$ century $^{2}$, almost all of the theoreticians who succeeded Chrysanthos based their thought on his fundamental principles. Thus, it is worth mentioning that in treatises that followed the Reform of 1814, repetitions are frequently detected, even of Chrysanthos' points that could be considered as scientifically problematic ${ }^{3}$.

\section{Chrysanthos' theoretical thought and the Enlightenment}

A number of scientific essays have proved that Chrysanthos' theoretical thought ideologically follows the basic ideas of the European Enlightenment ${ }^{4}$. Belonging to the progressive group of the Phanariots, he was naturally inspired by ideas of the Enlightenment and was also initiated into its ideological-philosophical principles ${ }^{5}$. This fact becomes more obvious, if one approaches his theoretical work attempting to detect the sources where he draws his historical material from. In the frame of this procedure, it is easy to realize that Chrysanthos uses not only valuable information from works that belong to the movement of the Enlightenment, but also utilizes specific methodological models and theoretical tools that directly refer to Western music culture. Simultaneously, according to the common practice followed in the circles of the Enlightenment's exponents, he resorts to the legacy of ancient Greek music and philosophy, in order to detect appropriate terminology. In specific, behind this practice one traces the ideological rhetoric about the authority

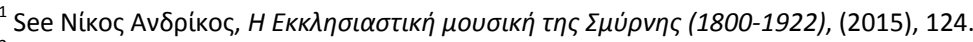

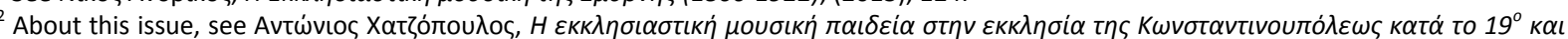

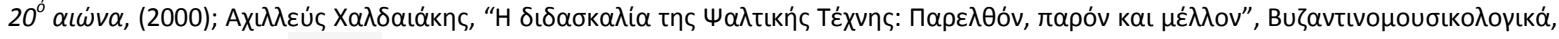

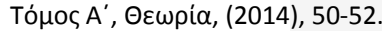

${ }^{3}$ Among others, the most indicative example was the repetition of Chrysanthos' misguided calculation-measurement of the basic scale's size. This issue became the reason for a wide discourse between important theoreticians of the $19^{\text {th }}$ century through the daily and periodical press and led to the convocation of the Music Committee of 1881. See Avסpíkos, 135-145.

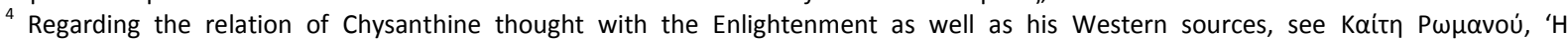

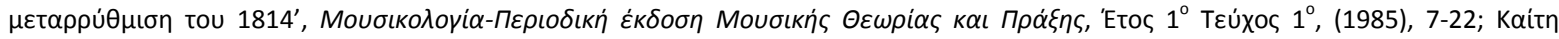

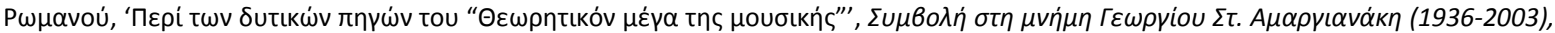

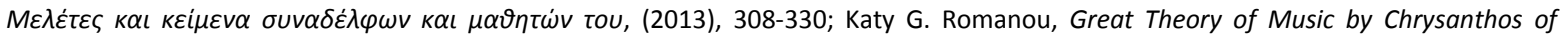
Madytos, translated by Katy Romanou, (1973), Introduction iv-xxxviii; Romanou Katy, 'A new approach to the work of Chrysanthos of

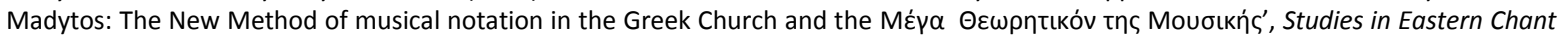

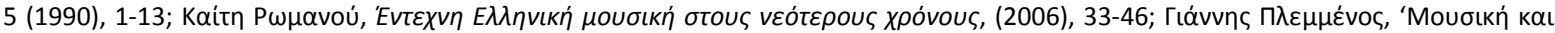

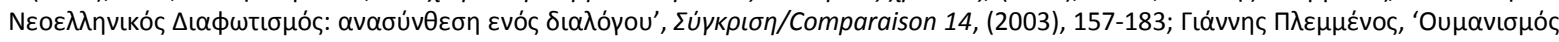

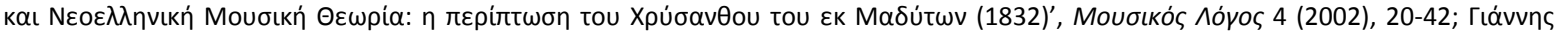

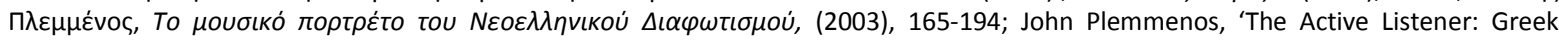

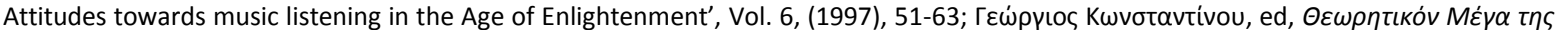

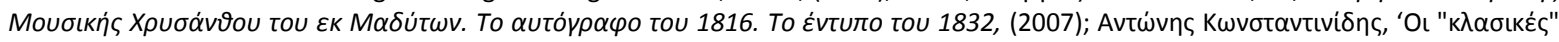

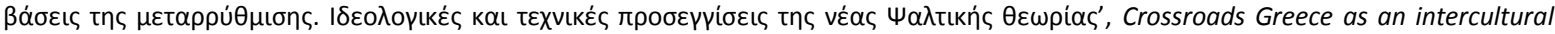

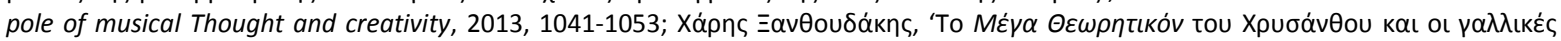

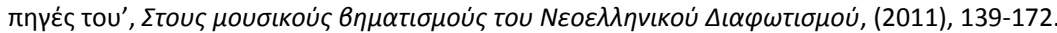

${ }^{5}$ About the basic principles of the Enlightenment, see John Robertson, The Enlightenment: A Very Short Introduction, (2015); Dan Edelstein, The Enlightenment: A Genealogy, (2010); Dorida Outram, The Enlightenment, (2013); Anthony Pagden, The Enlightenment and Why It

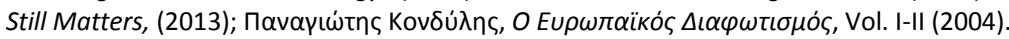


of Greek ancient culture-thought and the necessity of its revival. Actually, Chrysanthos, following the established methodology of his period, utilizes the theoretical material that comes from ancient Greek sources bypassing useful theoretical works about Ecclesiastical music of the Byzantine as well as the Ottoman period ${ }^{6}$. Therefore, one more feature that connects Chrysanthos' works with the movement of the Enlightenment is his effort to communicate his ideas to a wide audience. In order to accomplish this target, he transfuses -especially through his Eı $\sigma \alpha \psi \omega \gamma \eta$ - an obvious educational character to his work and simultaneously exploits the power and effectiveness of media such as the printed book.

\section{The Notational Reform in the frame of the developments in the music culture of Istanbul}

It is widely known that the invention of the new Parasemantiki system was the peak of a long-lasting procedure whose beginning can be detected in the $17^{\text {th }}$ century. The challenge of the construction of a more comprehensible notation system led to numerous attempts that had as common feature the detailed attribution of the written repertoire. Interestingly, corresponding attempts related to the construction and establishment of a notation system are detected at the same period in the field of Ottoman urban music. Actually, in the last decades of the $18^{\text {th }}$ century began a wide procedure of modernization of Ottoman music, affecting musical forms structurally and aesthetically, compositional production, performance and educational practices, instrumentarium, the content of modality, etc ${ }^{7}$. These radical changes relate to the wider reform procedure of the Ottoman Empire -widely known as Tanzimat- during the first half of the $19^{\text {th }}$ century in the fields of administration, bureaucracy, social life, religious rights of non-Muslim citizens, etc. At this point, it must be stressed that this whole modernization project undoubtedly had an orientation towards Western social-political models. So, it was impossible for the whole process not to affect aspects of culture and artistic production-expression, such as practices connected with music performance, education and compositional creation. Therefore, in the frame of the modernization of Ottoman music, the issue regarding the notation system and generally the transcription of the repertoire was put up for discussion. Although in the past numerous notation systems were introduced ${ }^{8}$, none was able to be established and widely accepted because of the obvious oral character of Ottoman music. So, the use of a notation system was never the absolute priority in the environment of Ottoman music masters, because the whole educational procedure followed the model of repetition and oral memorization known as Meş $k^{9}$. However, almost simultaneously with the invention of the new Parasemantiki, a corresponding phenomenon appeared in the circles of Istanbul's Armenians. Actually, the modern Armenian notation was invented by Hampartsum Limoncuyan in the period of Sultan Mahmut II $^{10}$. Therefore, the whole procedure of the notation system's establishment relates to the Catholic Armenian milieu of Istanbul as well as to the wide cultural and intellectual revival of the monastery of San Lazzaro in Venice ${ }^{11}$. Moreover, the invention of Hampartsum notation was integrated in the activity of the Armenian intelligentsia of Istanbul's urban area, amongst which the fundamental principles of the Enlightenment were widespread ${ }^{12}$. Although the Hampartsum notation was invented in order to accommodate the ritual needs of the Catholic Armenians, not only religious music was transcribed through this system. Like the Chrysanthine system, Hampartsum notation became the medium of transmission of an extensive oral material that belongs to the repertoire of Secular-Urban Ottoman music. So, the invention and dissemination of notation systems must be historically investigated within the frame of the general socio-politic transformation of the $19^{\text {th }}$ century Ottoman Empire. In addition, the reforms that are detected in the field of music could be considered as the "resonance" of the cultural and ideological "conversation" between Western Modernity and the pre-modern

\footnotetext{
${ }^{6}$ At this point it is useful to be reminded of the Protheories of Papadiki as well as works concerning the modality and notation of Ecclesiastical music, such as the essays of Gavriel Hieromonachos, Manuel Hrysaphes, Akakios Chalkeopoulos, Kyrillos Marmarinos, Apostolos Kontsas, etc. About theoretical works and treatises that were produced before the Reform of 1814, see Mapi $\alpha$ A $\lambda \varepsilon \xi \alpha \dot{v} \delta \rho o u$,

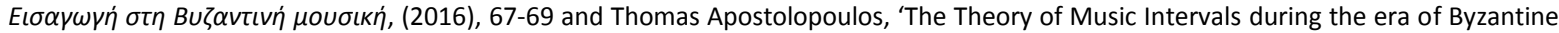
Maistores', Journal of the International Society for Orthodox Church Music, Vol. 3. Sect. II, (2018), 81-94.

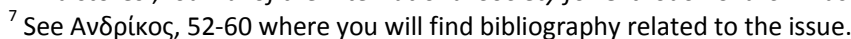

${ }^{8}$ About the notation systems of Ottoman music see Mehmet Öncel, 'Türk Musikisindeki Notasyonun Tarihsel seyri', Cumhuriyet Üniversitesi ilahiyat Fakültesi Dergisi (CÜiFD), XIX, 2, (2015), 207-222; Ahmet Feyzi, 'Türk Müziğinde notasyon ve miftah-ı nota', Rast Müzikoloji Dergisi, 6 (2), (2018), 1890-1913; Ruhi Ayangil, 'Western Notation in Turkish Music', Journal of the Royal Asiatic Society, Vol. 18, No. 14, (2008), 401-447.

${ }^{9}$ About the concept of Meşk, see Cem Behar, Aşk Olmayınca Meşk Olmaz. Gelenksel Osmanlı/Türk Müziğinde Öğretim ve Intikal, (2016).

${ }^{10}$ See Jacob Olley, Writing Music in Nineteenth-Century Istanbul. Ottoman Armenians and the Invention of Hamparsum Notation, PhD, (2017).

${ }^{11}$ Ibid.

${ }^{12}$ Ibid.
} 
Ottoman legacy. Because of this dialectical relationship, the Reform of 1814 in the Greek Orthodox Ecclesiastical Music must be comprehended within the wide spectrum of intercommunal relationships and interactions, between Greek Orthodox and Armenians, as well as of them both with the Muslim Ottoman ethnoreligious community.

\section{The relation between Orality and Textuality in Ecclesiastical music}

The reform of 1814 as well as the invention of music typography can also be approached using a philosophical methodology, in order to comprehend the "trajectory" from the oral pre-modern culture to the modern, text-oriented civilization. At this point, it must be stressed that Ecclesiastical Music despite its obvious oral mentality, simultaneously possesses an art-written character due to the use of a Notation System, the broad transcribed music philology (repertoire), the thousands of handwritten codices, the theoretical works and treatises, etc ${ }^{13}$. However, the entire handwritten material -music scores and theoretical works- does not have an autonomous entity ontologically, because the comprehension of its inner content requires an experiential relation with the oral dimension of the aforementioned music culture, through a long-lasting apprenticeship near the masters-exponents of this genre. Therefore, a dynamic-dialectical relation between the written sources and the oral aspect of Ecclesiastical Music can be observed ${ }^{14}$. The stenographicminimalistic character of the Old Notation System as well as the tendency of theoreticians to avoid the deterministic presentation of theoretical phenomena -especially regarding the intervallic material- reinforces the need of Ecclesiastical Music to refer to the pre-modern oral cultures. At this point, it should become clear that the existence of written archival material must not be considered as antinomic in relation to the dominant position that orality possesses in this culture. Actually, in the past, the use of various methods of writing was not a rare phenomenon in the frame of oral-pre-modern communities. So, in the field of Ecclesiastical music it is possible to detect a coexistence of written and oral culture. The relationship between orality and textuality in Ecclesiastical music would be misunderstood if it is comprehended as an inflexible-dogmatic dipole. On the contrary, the written sources include only the necessary information to be used as a visualized attribution of the performance practices. The repertoire's transcriptions function as a mnemonic code that provides the performer with the appropriate stimulus to revoke from their memory the oral material that they have "stored" through their long-time experiential relation with the performance ${ }^{15}$. Therefore, the accuracyfunctionality of written theoretical works depends on the extent that they succeed in the description, categorization, analysis and annotation of the phenomena that are detected in the field of performance. As is the case with notation systems, theoretical thought cannot be understood independently of the experiential "knowledge" that renders Orality as the most crucial factor of Ecclesiastical music. In fact, the total result of any music experience has an absolute sonic character. So, any written attribution of the performance's essential content must be understood as a conventional visual depiction of a particular sonic environment. In addition, especially concerning music cultures that are characterized by an obvious oral element, the music score cannot possibly be identified with the concept of the Musical Work ${ }^{16}$. A transcription, even if it is extremely detailed, does not have the ability to capture all of the interpretative information that is detected in the field of performance. Moreover, according to the pre-modern notion of the Musical Work, a variety of idiomatic as well as idiosyncratic executive approaches should preferably be considered as an inextricable part of a specific composition. Hence, the oral interpretative dimension of a piece does not constitute extrasupplemental information about the composition, but an ontologically necessary element of its essence. Therefore, a music score even in the detailed New Parasemantiki has the ability to describe the main compositional idea while simultaneously implying the -"hidden" behind the lines- oral information. Thus, necessary for the execution of a piece is not only its transcript version but also the knowledge of the overall interpretative details that comes from oral experience ${ }^{17}$.

\footnotetext{
${ }^{13}$ See Nikos Andrikos, 'The dialectical relation between written melismatic repertory and oral interpretative pluralism in the Greek Orthodox Ecclesiastical Music', Melismatic Chant Repertories, (2020), (to be published).

${ }^{14}$ Ibid.

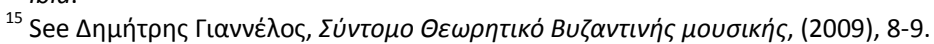

${ }^{16}$ About the concept of Musical Work, see Lydia Goehr, The Imaginary Museum of Musical Works. An Essay in the Philosophy of Music, (2007).

${ }^{17}$ See Andrikos, "The dialectical...".
} 
As stressed above, the relation between orality and textuality in the field of Ecclesiastical music is bidirectional. So, just as the oral information influences the score's interpretation, the effect of the written material can be detected in the performance. In the instance of the Chrysanthine notation system, if the melodic material's transcription is extremely detailed, it is possible to define the execution, at the same time confining the performer's interpretative alternatives ${ }^{18}$. The transition of Ecclesiastical music from an oral mentality to a corresponding modern, text-oriented one, through the Chrysanthine notation system and theory will be analyzed below.

\section{The characteristics of Orality and the effectiveness of Textuality (manuscript-printed book)}

According to Ong "Oral expression can exist and mostly has existed without any writing at all, writing never without orality"19. Actually, Walter Ong's book Orality and Literacy -among others- deals with the most characteristic elements of Orality as well as with the cultural and ideological consequences of the establishment of Writing in modern society. Plato's hesitation regarding the use of Writing is well-known. In the "Seventh Letter" in Phaedrus ${ }^{20}$, Plato's Socrates argues that writing destroys memory ${ }^{21}$. Thus, if one approaches the literary legacy of the pre-modern era it is easy to realize the significant role that Orality plays. So, the use of stereotypic-repetitive formulas was widespread even in the field of performance, for example in the recitation of epics by poets. Actually, the term "rhapsodize" ( $\dot{\alpha} \alpha \omega \delta \varepsilon \tilde{l v})$ that means "to stitch songs together" ${ }^{22}$ highlights the flexible management of the oral material according to performative circumstances. So, from this aspect, the basic characteristics of Orality are "the dynamism of the oral lingual deliveryutterance, its mobility, its continuous changeability, its ability to participate, its function according to the individual conditions, its experiential-empathetic dimension ${ }^{\prime 23}$.

Ong argues that Writing is a procedure that could be characterized as the "Technologizing of the Word", because it is the most drastic method of achieving "the reduction of dynamic sound quiescent space ${ }^{\prime 24}$. So, Writing is the media that not only transfers information through space and between persons, but also creates new ways of thinking and mediates between the individual and social existence ${ }^{25}$, restructuring consciousness more than any other single invention ${ }^{26}$. According to Ong, a gradation must be recognized in the effectiveness of Writing. So, the manuscript as a medium carries a dynamic character keeping alive its discourse-interaction with oral culture. Thus, a handwritten work allows the reader to interfere with the main corpus of the text, through interpretative comments in the margins, editing, insertions, additions, erasures, etc $^{27}$. In contrast, typography presents an absolute, static, closed to interventions shape of the text, considering that "Writing moves words from the sound world to a world of visual space, but print locks words into position in this space ${ }^{\prime 28}$. Furthermore, print philosophically ensures the ontological substance of words as visible and unchangeable entities. Actually, the printed book as media owes its effectiveness to the high grade of the fixation of the symbolic form ${ }^{29}$. The cultural distancing from the Oral mentality as well as the displacement of communication's center of gravity to the print civilization has a variety of consequences that -among othersare related to the function of the senses. According to Ong "since the shift from oral to written speech is essentially a shift from sound to visual space, here the effects of print on the use of visual space can be the central, though not the only, focus of attention ${ }^{\prime 30}$. In the case of music, this aspect must be considered as very crucial regarding the comprehension of the way in which the senses participate in the whole procedure of the expression-perception of music. So, as will be analyzed below, due to the catholic establishment of the print,

\footnotetext{
${ }^{18} \mathrm{Ibid}$.

${ }^{19}$ Walter Ong, Orality and Literacy. The Technologizing of the Word, (2005), 8.

${ }^{20}$ Ibid, 274-277.

${ }^{21} \mathrm{lbid}, 25,78$.

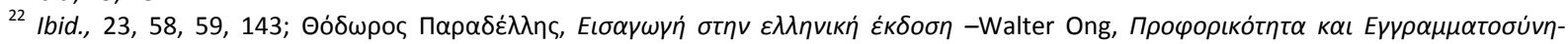
(Introduction of the Greek edition of the Ong's book), (2019), xvi.

${ }^{23} \mathrm{lbid}$., xv.

${ }^{24}$ Ong, 80 .

${ }^{25}$ See $П \alpha \rho \alpha \delta \dot{\varepsilon} \lambda \lambda \eta \varsigma$, xii.

${ }^{26}$ See Ong, 77.

${ }^{27}$ Ibid., 130

${ }^{28} \mathrm{lbid} ., 119$.

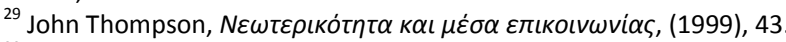

${ }^{30}$ Ong, 116. See also П $\alpha \rho \alpha \delta \varepsilon \dot{\lambda} \lambda \eta \eta$, xiv.
} 
the central sense of a variety of procedures concerning music is no longer the sense of hearing, but the sense of vision.

\section{The Chrysanthine notation system -a process from Orality to Textuality}

As stressed above, Ecclesiastical music up until the Reform of the Three Masters, despite its doubtless scholarly side, was characterized by an intense oral dimension. The aforementioned oral character is obvious in the fields of performance and composition, as well as in the way theory functioned and was perceived. Actually, only the basic compositional "body" was depicted through the music score, while elements concerning the executive parameters such as intervallic management, rhythmic attribution and ornamentation were implied. So, crucial-necessary elements related to the interpretation were not defined through notation. Melodic schemes such as Megalai Hypostaseis and Thematismoi functioned as stenographic attributions of extensive melismatic themes. Correspondingly, the minimalistic depiction of melodic phrases facilitated their evocation from the executant's memory. At this point it is worth remembering that music notation functions as a mnemotechnic method in the frame of oral memorization ${ }^{31}$. Therefore, the performance's independence of the music score contributes to interpretative pluralism. Actually, the variety of interpretative approaches referring to the sonic experiences (direct or mediated) of chanters proves the significance of Orality in Ecclesiastical Music ${ }^{32}$. Thus, the attribution of extensive melodic themes from memory becomes the "embankment" against the "scholastic" standardization-crystallization of the phraseological material's interpretative attribution. Therefore, the music score could be comprehended as a guide that facilitates the whole performative or educational procedure, functioning as a brief visualized attribution of the compositional core. In fact, even in the instances when the transcription is extremely detailed, the music score's capability is finite. So, like any Writing system ${ }^{33}$, the music score, despite its potential regarding the transcription of sonic material, is unable to attribute the way-sense of its specific execution. Thus, Notation undoubtedly possesses the ability to depict a musical idea but not to exactly attribute the way of its expression in the field of performance. So, although it is possible to produce written material that can depict a music theme that has been executed, this written source cannot accurately express the mood that the theme was performed with. Due to this reality, the written material of Ecclesiastical music can be said to contain only the necessary notes that describe the structural substance of a Musical Work, implying the whole oral-interpretative information that is detected in the field of performance.

The New Method, despite its analytical attitude, maintains the fundamental principles regarding the dynamic relation between written material and Orality. Thus, even when the transcription is extremely detailed, the written material refers to an amount of specific phrases whose interpretative content must already be known by the performer. However, the analytical potential of the Chrysanthine notation system seems to "reduce the distance" between a static transcription and the performance's oral reality.

If one attempted to philosophically interpret the Chrysanthine notation system's function applying Ong's theory, he could characterize it as a case of the "Technologization of the Musical Word". In fact, Chrysanthos, following previous attempts of Parasemantiki's analysis-simplification, regarding repertorial transcription, creates a technological model that successfully balances between the pre-modern and modern civilization. So, the New Parasemantiki referring to the concept of Orality does not interrupt its connection with the pre-modern oral cultures' mentality. Simultaneously, the Chrysanthine system based on the Enlightenment's principles, attempts to rationalize the notation's function in order to render Ecclesiastical music part of the modern Writing civilization of the West. Actually, this can easily be proved by Chrysanthos' works -among others- due to their emphatic "promotion" of the written and theoretically-rationally analyzed side of Ecclesiastical music.

\footnotetext{
${ }^{31}$ Ong, 56.

${ }^{32}$ Regarding Orality and Interpretation as well as the concept of Yphos in the frame of Ecclesiastical music, see Alex-Konrad Khalil, Echoes of

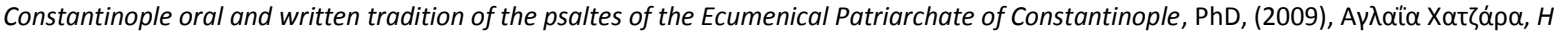


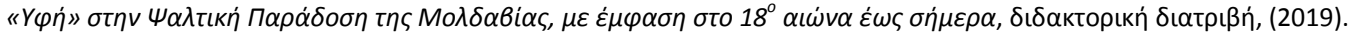

${ }^{33}$ See $\Pi \alpha \rho \alpha \delta \varepsilon \dot{\lambda} \lambda \eta \varsigma, x x$.
} 
Another important factor that reinforced the establishment of Textuality in the field of Ecclesiastical music was the invention of music typography. So, through printing technology, the New notation as well as the theoretical views of Chrysanthos were crystallized as a complete system, at the same time obtaining the corresponding authority of a "reference source". Actually, the access to knowledge by the masses was one of the most important targets of the Enlightenment. So, typography became the appropriate tool for the dissemination of new ideas to a variety of social groups. Even if one disputes the availability of the printed book to a wide audience because of its price, the lists of subscribers attest that printed collections accomplished to reach via music networks the crucial-central nodes, drastically affecting a variety of procedures such as the repertoire's dissemination, stylistic syncretism, compositional intertextuality, bi-musicality, etc ${ }^{34}$. At this point it should be pointed out that the reading of the printed book refers to a private procedure. In fact, it was through typography that the approach of written sources in the frame of private life was facilitated ${ }^{35}$. Actually, this radical change relates to another fundamental idea of the Enlightenment, concerning the emancipationliberation of the person and the establishment of the modern individual identity.

\section{The rationalization of Theory}

As stressed above, Theory is the procedure that aims to systematically present, annotate, categorize and analyze the phenomena that are detected in the field of performance and repertoire. Therefore, Theory does not possess an autonomous substance due to its absolute reference to performance practices. Thus, Theory can be accepted as an entirely mental product that emerges after a process of rationalizedsystematized comprehension of the music reality ${ }^{36}$.

Despite the dependence of Theory on practical experience, a lot of contradictions between Theory and Praxis can be detected in the frame of the theoretical production of Ecclesiastical music. In these instances, Theory does not accomplish to accurately describe a variety of phenomena that are detected in the repertorial material and the field of performance. So, the phenomenon of antinomy between the Theoretical word and the reality of performance can be observed especially regarding a variety of issues that concern the structural as well as the intervallic substance of Echoi.

The new concept that Chrysanthine thought introduces is a deterministic mentality about the attribution of phenomena. So, Chrysanthos attempts to define the size of intervals using the arithmetic method. Therefore, despite the doubtless pedagogical dimension of this practice, the whole mentality leads to an absolutely different -in comparison with the pre-Reform treatises- comprehension of the phraseological material's intervallic behavior. As is widely known, the theoretical works written before the Reform of 1814 do not deal with an absolute intervallic determination. On the contrary, the description of the melodic material

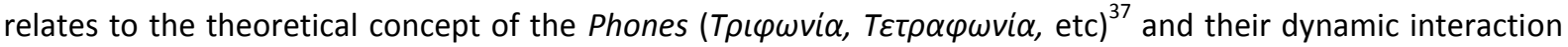
with the degrees. The values of the intervals are not defined, so their practical attribution in the frame of performance was absolutely dependent on oral practices ${ }^{38}$. So, Chrysanthos through the application of intervallic definition -especially in the frame of the octavic scale- attempted to prove that Eastern-Modal Ecclesiastical music can be methodologically presented-comprehended according to rational tools, such as intervallic values, octavic scales, etc. Contemporary studies related to Ecclesiastical music ${ }^{39}$ and corresponding music cultures of the East ${ }^{40}$, have scientifically proved the phenomenon of intervallic fluidity-flexibility through the use of computational-systematic models. Thus, the pitch of a degree usually changes according to the

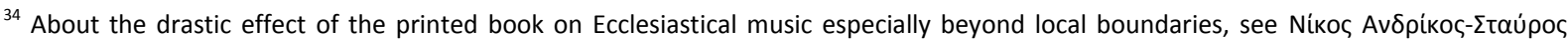

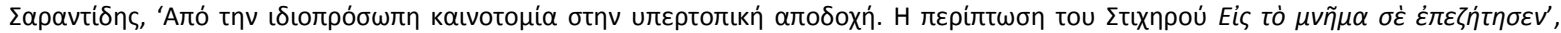

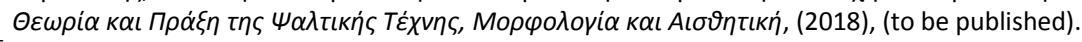

${ }^{35}$ See Ong, 128.

${ }^{36}$ Nikos Andrikos, 'Towards a Re-approach of Makam Theory Based on Practice and Performance: The Case of the Segah Phenomena', Etnomüzikoloji Dergisi/Ethnomusicology Journal, 3 Issue: 2, (2020), 224, 225, 231.

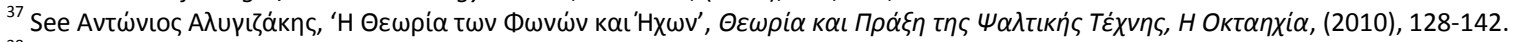

${ }^{38}$ About this issue, see Apostolopoulos.

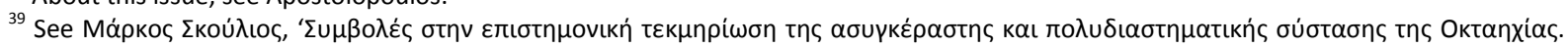

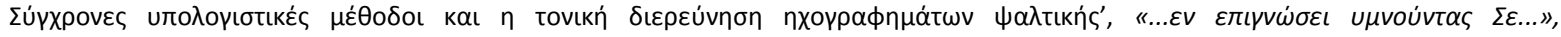

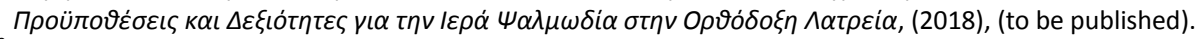

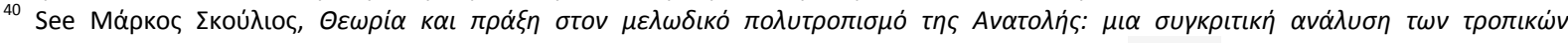

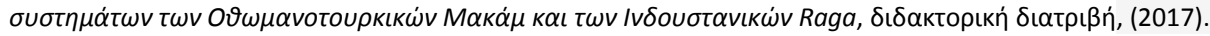




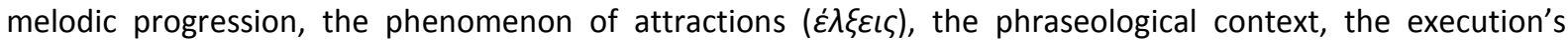
tempo, the idiomatic and individual interpretative elements, the composition's form-structure-historical dimension, etc. So, even via the most valid measurements -when they accomplish to calculate the intervals for any instance- it is not possible to construct a reference unit -like the octavic scale- that contains static-definite intervals. The intervals have the particularity of contracting and dilating even by the same performer, within the same piece that is executed in a specific time. Therefore, the phenomenon of intervallic pluralism can be observed not only between different performers or different pieces' executions but also in the instances of the interpretation of a specific composition. For example, in the frame of a particular melodic phrase despite the repeated use of the same degree, the execution of this degree may be absolutely different, depending on the wider phraseological context. So, intervallic changeability, being one of the most important elements of Ecclesiastical music, does not give the opportunity of any a priori static-absolute definition of the intervals. However, Chrysanthos' practice of defining intervals was widely embraced by theoreticians up until now, inducing a plethora of consequences on the mentality as well as the performance practices.

\section{The process from Theory and notation to Performance}

As underlined above, the theoretical word about a music genre is a reflective procedure that comes after the performance and musical creation. Correspondingly, notation functioned more as a sum of notes that facilitates the use of memorizable phrases than as an absolute depiction of a compositional idea or performative approach. The New Notation System, the Chrysanthine Theory as well as the invention and dissemination of typography contributed to the establishment of Textuality in the field of Ecclesiastical music. The crucial question that emerges concerns the relation between Theory and Praxis. How can Theory affect the performance due to the influential power of textuality? Is written Theory simply an attempt of oral performance's annotation or is it a "dogmatic causality" that determinately interferes with the performance? Can the performance's "trajectory" remain unaffected by a variety of subjective-individual and probably nonscientific theoretical aspects?

Indeed, if one attempts to examine the contemporary reality of Ecclesiastical music in the fields of performance and education, they will notice the crucial role that the written material (treatises, printed scores, methods, etc) plays. In older generations one could often find high level professional chanters who had obtained experience from performance without any theoretical and notational knowledge. So, despite their ignorance of Parasemantiki's use, they were able to practically highlight the most important elements that are placed in the core of Ecclesiastical music's interpretation. In contrast, nowadays the existence of chanters who have obtained a very rich theoretical background and are very capable in the use of the music score is common. However, their interpretative ways can be characterized as deficient due to their absolute dependence on the score, the limited experience in the field of performance and the absence of any reference to the oral material. In fact, Ecclesiastical music as a performative art carries an obvious practical character. However, nowadays due to the ideological domination of the literate chanter's model, the chanters who don't use the music score usually are disparagingly characterized as praktikoi psaltes.

Chanters who belong to the older generation -especially with connections to the Patriarchate of Constantinople ${ }^{41}$ or the monastic communities of Athos- used to memorize and execute a considerable amount of common short-syllabic Troparia and characteristic phrases of Sticherarion and Papadiki without the use of notation. In addition, they were very competent in the technique of the Biblical Text's melodic recitation

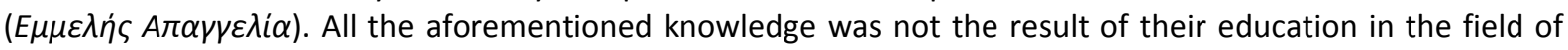
formal music learning (conservatories, music schools, etc), but the "fruit" of their long-time apprenticeship next to masters in the field of ritual performance. In fact, in the frame of Ecclesiastical music the space of education is identified with the space of performance ${ }^{42}$. Indeed, in contrast with other music genres, in Ecclesiastical

\footnotetext{
${ }^{41}$ In the frame of performance in the Patriarchate the use of the music score is very rare. Actually, notation is used only in some instances, such as the execution of wide-melismatic repertoire of Papadiki. This practice does not indicate any absence of the repertoire's knowledge. On the contrary, performance by heart highlights the chanters' acquaintance with the repertoire as well as the experiential knowledge-comprehension of the wider esthetic and stylistic parameters of interpretation.

${ }^{42}$ One can conceive the specificity that this reality carries if they imagine this practice to be placed in the field of performance of other especially art- music genres. Indeed, the participation of a beginner-low level student in a concert among professional musicians without rehearsals could be comprehended as extremely peculiar.
} 
music even a beginner student can obtain their special role in the performance. So, apart from listening carefully to the masters' interpretations, a student can also contribute to the performance, executing the isocratema (drone) and the canonarchema, "following" the repetitive cadencial phrases, intoning Biblical Texts from Psalterion, etc. Actually, the chanters who follow the above method first learn to chant and then start learning the notation, theory and standard repertoire. On the contrary to past practices, nowadays the learning procedure begins from the use of notation. So, the whole educational experience is based on the music score's knowledge and not on the experiential relation with the performance's Orality. In addition, due to this mentality, any interpretative approach must stem from the transcription. The ornaments must be executed in a

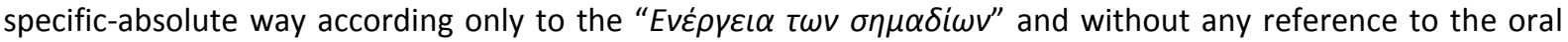
dimension of the compositional corpus. So, a character or a melodic scheme can be executed in the same way every time independent of the inner phraseological structure and the execution's tempo. So the unique factor that determines the whole interpretative procedure is the music score. Such an executive approach restricts the spectrum of possible interpretational alternatives while also "weakening" the expressive potential. Frequently, the skill of score reading -the ability to approach a wide portion of the repertoire- creates the illusion of "knowing" the repertoire. In this case, reading the score is identified with the repertoire as well as the ability of its execution. Correspondingly, in the case of very detailed transcriptions, problems of comprehension of the melodic schemes appear. In these instances, performers without wide practical experience may manage the main melodic corpus and its ornaments in the same way, unable to discern between them according to their compositional gravity-significance. The analysis is not included as autonomous-extra notes but contains the expressional "resonance" of the main melodic theme. So the ornaments are usually executed discreetly with less stress than that given to the main melodic core. However, the holistic transcription of the theme (main corpus and ornaments) can lead to performances that do not refer to the memorizing attribution of the phrases but to a "note to note"- metrophonic execution.
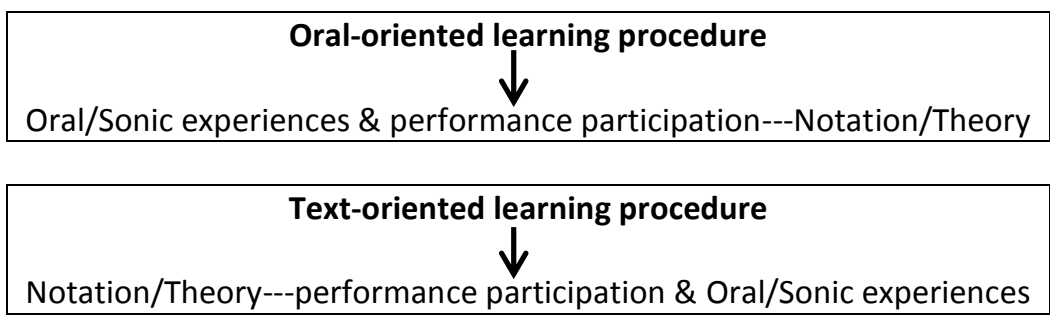

The absolute priority of this text-oriented mentality can have various consequences on the repertoire's comprehension and interpretative attribution. So, approaches that identify the music score with the Musical Work and restrict the concept of interpretation to the frame of the score's execution, can be the reason of the emergence of phenomena such as a dogmatic depedence on written information. In this instance, the whole performance may be formed according to a mechanical execution of the signs $(\sigma \eta \mu \alpha \dot{\alpha} \delta \alpha)$ without taking into account other important interpretative factors such as the piece's genre and stylistic profile, the execution's tempo, the holistic comprehension of the melodic material, etc. According to this approach every sign requests a specific way of execution independent of the wider musical context. Correspondingly, the same phenomenon can be detected regarding intervallic attribution, when the degrees' attractions are not incorporated in the natural melodic flow of the piece, but their exaggerated execution creates numerous peculiar -irrelevant to oral reality- sonic environments. In these cases, the main impression is that music does not obtain any artistic autonomy seeing that the performance's aim is not expression, but instead, the proof and application of a specific theoretical model.

The priority of the text-oriented side of Ecclesiastical music brings to the "forefront" Ong's theory about the role of the senses during the process from oral experience to printed production. The use of a plethora of written sources establishes a mentality that connects more with the modern visual civilization than the sonic environments of the oral communities. Due to this reality, the common impression is that contemporary Ecclesiastical music is an art that relates more with the sense of vision than with the sense of hearing. In fact, Chrysanthine thought attempts to balance between Orality and Textuality, practice and theory, sonic and visual, pre-modern and modern, experiential-direct and mediated-indirect, minimalism and 
specificity, art expression and rationalization, simultaneously bridging gaps and breaking stereotypic dipoles through a variety of dynamic-dialectical relations.

\section{Bibliography}

Andrikos, Nikos, 'The dialectical relation between written melismatic repertory and oral interpretative pluralism in the Greek Orthodox Ecclesiastical Music', IMS Study Group of the Christian East and Orient, First International Symposium: Melismatic Chant Repertories, Thessaloniki, 12-14 June 2020, (to be published).

Andrikos, Nikos, 'Towards a Re-approach of Makam Theory Based on Practice and Performance: The Case of the Segah Phenomena', Etnomüzikoloji Dergisi/Ethnomusicology Journal Yıl/Year: 3 • Sayı/Issue: 2, Etnomüzikoloji Derneği, Ethnomusicology Association, (2020), 224-243.

Apostolopoulos, Thomas, 'The Theory of Music Intervals during the era of Byzantine Maistores', Journal of the International Society for Orthodox Church Music, Vol. 3. Sect. II: Conference papers, Ed. Ivan Moody \& Maria Takala-Roszczenko, (2018), 8194.

Ayangil, Ruhi, 'Western Notation in Turkish Music', Journal of the Royal Asiatic Society, Third Series, Vol. 18, No. 14, Cambridge University Press on behalf of the Royal Asiatic Society of Great Britain and Ireland (2008), 401-447.

Behar, Cem, Aşk Olmayınca Meşk Olmaz. Gelenksel Osmanlı/Türk Müziğinde Öğretim ve İntikal, İstanbul: Yapı Kredi Yayınları, (2016).

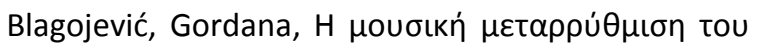

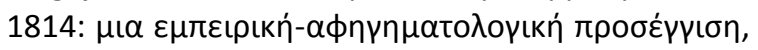

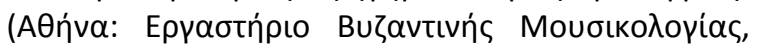
ЕКПА, 2019), 2019.

Edelstein, Dan, The Enlightenment: A Genealogy, (Chicago: University of Chicago Press, 2010), 2010.

Feyzi, Ahmet, 'Türk Müziğinde notasyon ve miftah-ı nota', Rast Müzikoloji Dergisi, 6 (2), (2018), 18901913.

Goehr, Lydia, The Imaginary Museum of Musical Works. An Essay of in the Philosophy of Music, (Oxford: Oxford University Press), 2007.
Khalil, Alex-Konrad, Echoes of Constantinople oral and written tradition of the psaltes of the Ecumenical Patriarchate of Constantinople, PhD, University of California, San Diego, (2009).

Olley, Jacob, Writing Music in Nineteenth-Century Istanbul. Ottoman Armenians and the Invention of Hamparsum Notation, PhD, King's College London, (2017).

Öncel, Mehmet, 'Türk Musikisindeki Notasyonun Tarihsel seyri', Cumhuriyet Üniversitesi İlahiyat Fakültesi Dergisi (CüiFD), XIX, 2, (2015), 207-222.

Ong, Walter, Orality and Literacy. The Technologizing of the Word, (London and New York: Routledge, Taylor \& Francis Group), 2005.

Outram, Dorida, The Enlightenment, 3rd ed. (Cambridge: Cambridge University Press, 2013), 2013.

Pagden, Anthony, The Enlightenment and Why It Still Matters, (Oxford: Oxford University Press, 2013), 2013.

Plemmenos, John, 'The Active Listener: Greek Attitudes towards music listening in the Age of Enlightenment', British Journal of Ethnomusicology, Vol. 6, British Forum of Ethnomusicology, (1997), 51-63.

Robertson, John, The Enlightenment: A Very Short Introduction, (Oxford: Oxford University Press, 2015), 2015.

Romanou, Katy, 'A new approach to the work of Chrysanthos of Madytos: The New Method of musical notation in the Greek Church and the Méya

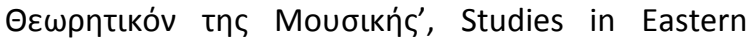
Chant 5, (1990).

Romanou, Katy, Great Theory of Music by Chrysanthos of Madytos, translated by Katy Romanou, Master Thesis, School of Music, Indiana University, Indiana (1973). 


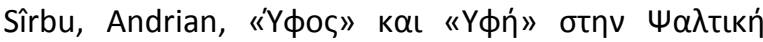

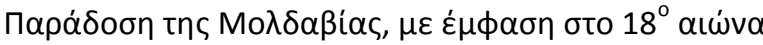

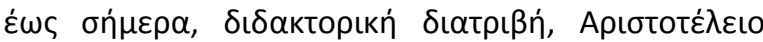

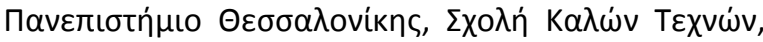

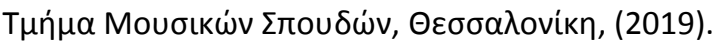

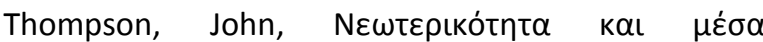

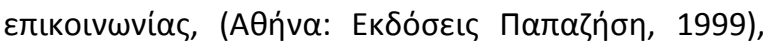
1999.

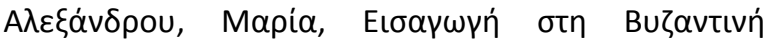

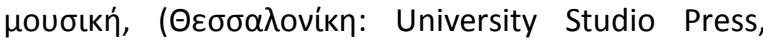
2016), 2016.

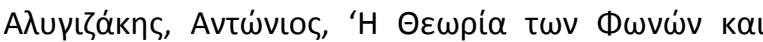

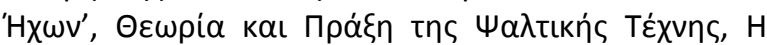

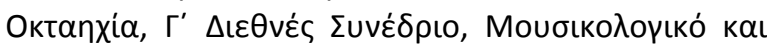

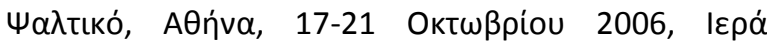

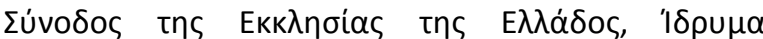

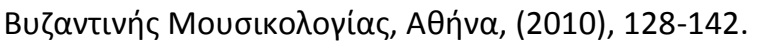

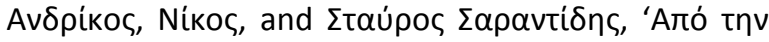

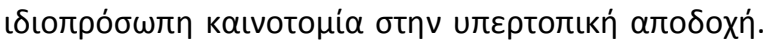

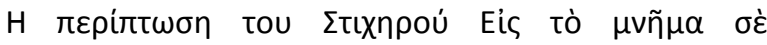

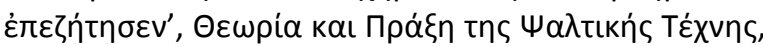

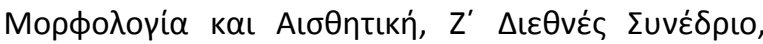

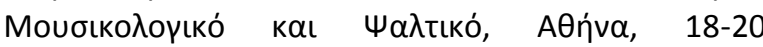

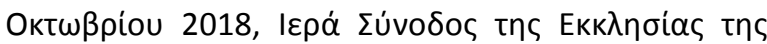

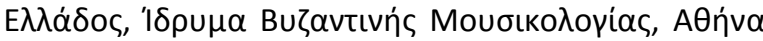
(2018), (to be published).

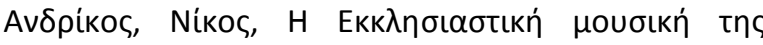

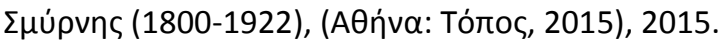

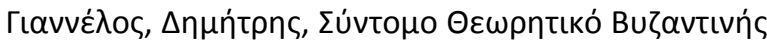

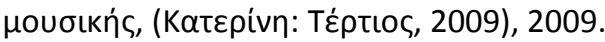

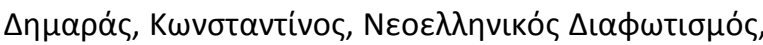

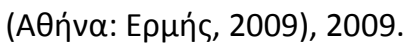

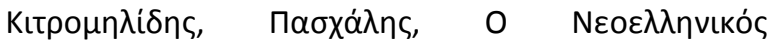

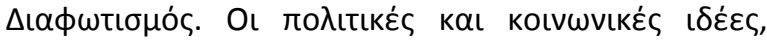

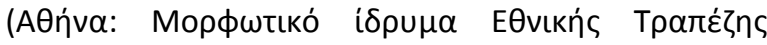
(MIET), 2009), 2009.

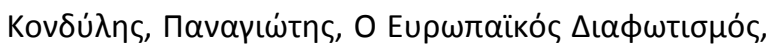

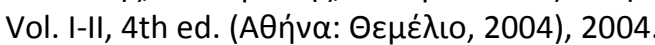

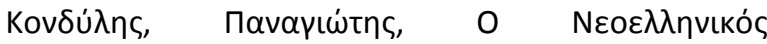

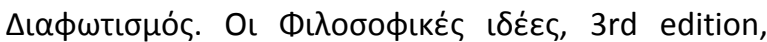

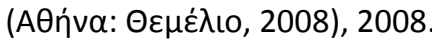

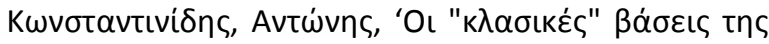

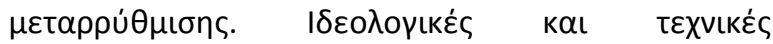

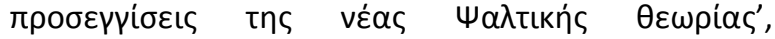
International Musicological Conference, Crossroads Greece as an intercultural pole of musical Thought and Creativity, Aristotle University of Thessaloniki, School of Music Studies, International Musicological Society (I.M.S.), Regional Association for the Study of Music of the Balkans Thessaloniki, 6-10 June 2011, eds. Evi Nika-Sampson, Giorgos Sakallieros, Maria Alexandru, Giorgos Kitsios, Emmanouil Giannopoulos, Thessaloniki, 2013, 1041-1053.

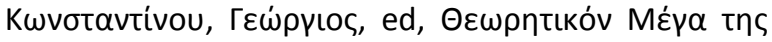

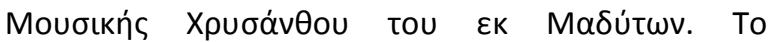

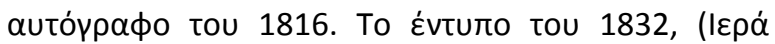

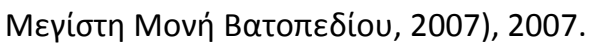

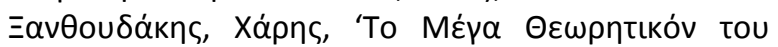

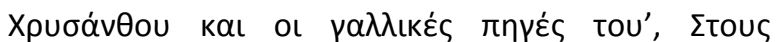

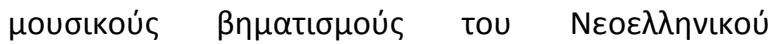

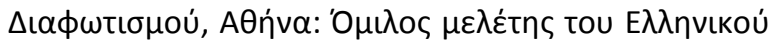

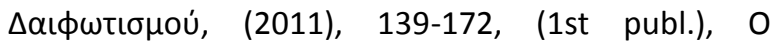
Epavıotńs, 26, (2007), 79-104.

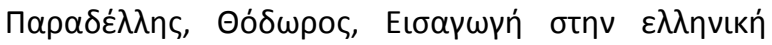

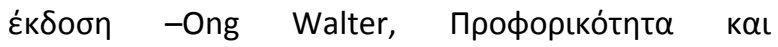

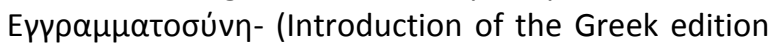

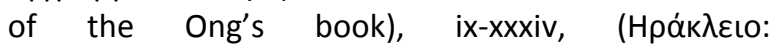

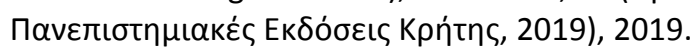

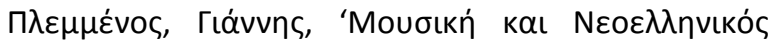

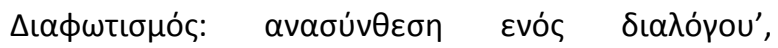

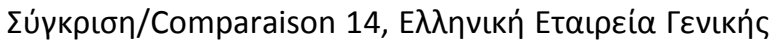

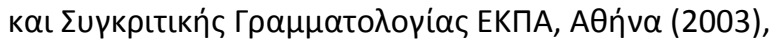
157-183.

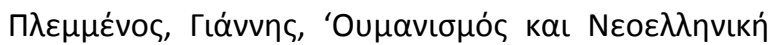

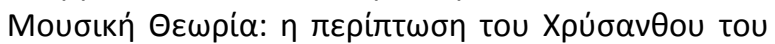

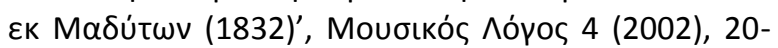
42.

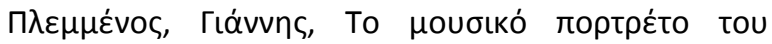

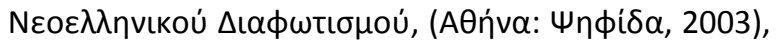
2003.

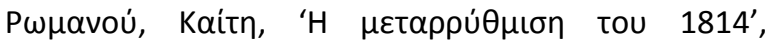

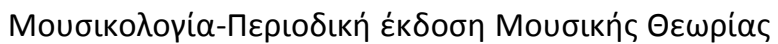

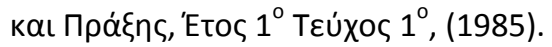

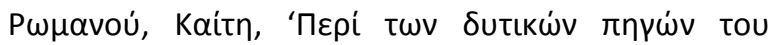

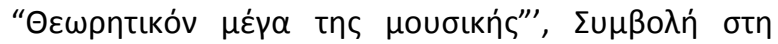

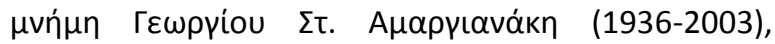

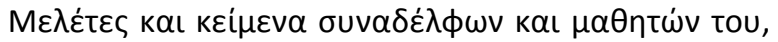
(2013), 308-330.

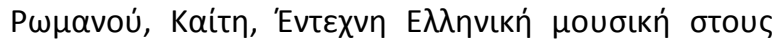




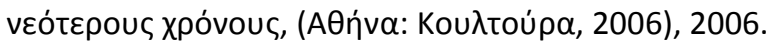

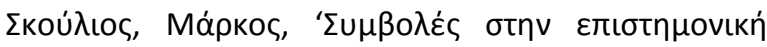

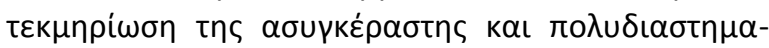

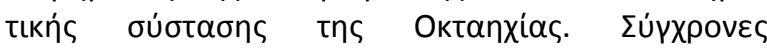

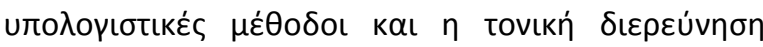

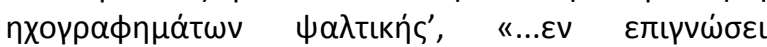

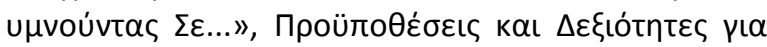

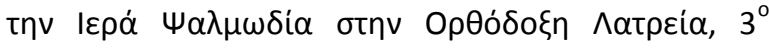

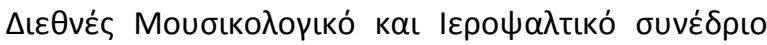

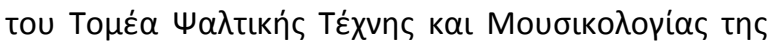

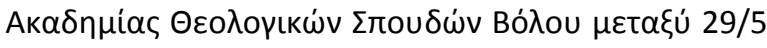

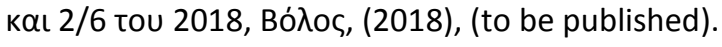

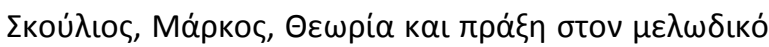

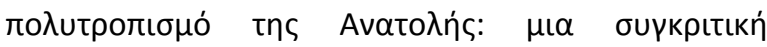

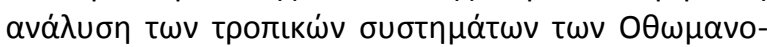

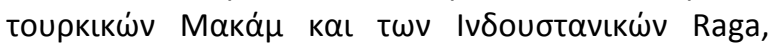

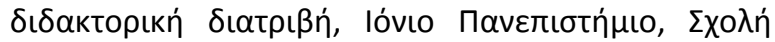

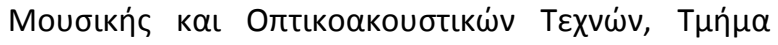

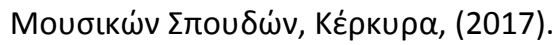

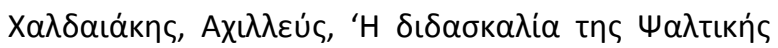

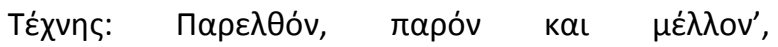

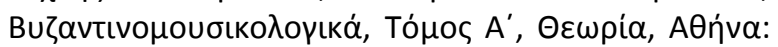

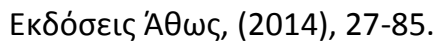

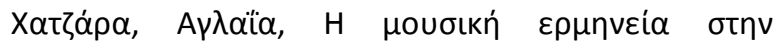

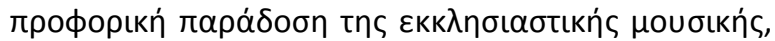

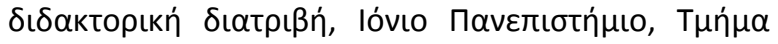

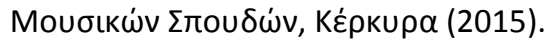

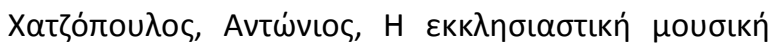

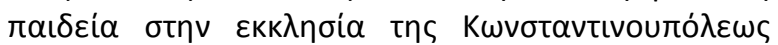

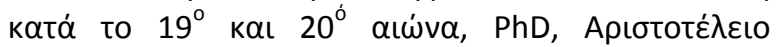

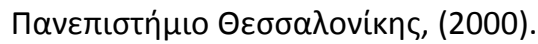

